\title{
Estudo exploratório do uso da vinhaça ao longo do tempo. II. Características da cana-de-açúcar
}

\author{
Janaina Paulino ${ }^{1}$, Cornélio A. Zolin², Altair Bertonha ${ }^{3}$, \\ Paulo S. L. Freitas ${ }^{3} \&$ Marcos V. Folegatti $^{1}$
}

\begin{abstract}
RESU MO
0 presente trabalho foi realizado em Cidade $\mathrm{G}$ aúcha, PR, e teve como objetivo avaliar a resistência mecânica do solo, compactação, níveis de cálcio, magnésio e potássio, além da saturação de bases no solo e a densidade de raízes de cana-de-açúcar fertirrigados com vinhaça durante 1, 2, 3, 4, 12 e 20 anos e em uma área que não recebeu aplicação. A compactação foi avaliada com um penetrômetro de cone até $0,50 \mathrm{~m}$ de profundidade; a cada $0,02 \mathrm{~m}$ as análises químicas foram realizadas em amostras de solo coletadas entre 0 e 0,20 e 0,20 e 0,40 m de profundidade e a densidade de raízes avaliada com a pesagem de massa seca das raízes extraídas de monólitos de solos retirados a cada 0,10 m de profundidade, até $0,50 \mathrm{~m}$. A maior resistência mecânica do solo ocorreu na área com vinte anos de aplicação de vinhaça. A concentração de cálcio decresceu após 2 anos de aplicação de vinhaça, acompanhando a fertilidade atual dos solos, não tendo ligação direta com a produtividade; já a concentração de potássio no solo apresentou relação direta com a produtividade; A quantidade de raízes no perfil do solo aumentou com o tempo de aplicação de vinhaça.
\end{abstract}

Palavras-chave: aplicação de vinhaça, produtividade, resistência mecânica do solo, enraizamento

\section{Exploratory study of the stillage use along the time. II. Characteristics of the sugarcane crop}

\begin{abstract}
This work was conducted in the Cidade Gaúcha PR, with the objective to evaluate the mechanical resistance of soil, the levels of calcium, magnesium, potassium, base saturation in the soil, the roots distribution and yield of sugarcane fertigated with wastewater (stillage) of sugarcane industry for 1, 2, 3, 4,12 and 20 consecutive years and a control without application. The soil compaction was evaluated with penetrometer cone to $0.50 \mathrm{~m}$ depth in intervals of $0.02 \mathrm{~m}$. The results of chemical analysis of soil samples collected between the depths of 0 to 0.20 and 0.20 to $0.40 \mathrm{~m}$ were evaluated. The root density was evaluated with the weight of the dry matter of roots with the monolith method retreats to each 0.10 $\mathrm{m}$ depths to $0.50 \mathrm{~m}$. The high soil mechanical resistance occurred where wastewater of sugarcane industry was applied for 20 years. The concentration of calcium decreased after two years of application of wastewater, accompanying the fertility of the soils not showing direct connection with the productivity as well as the magnesium. The concentration of the potassium in soil presented linear relation with the productivity. The roots of the sugarcane presented a direct relation with the application time of wastewater of sugarcane industry.
\end{abstract}

Key words: application of wastewater of sugarcane's industry, productivity, soil mechanical resistance, rooting 


\section{INTRODUÇÃO}

Considerada um resíduo pelas destilarias, a vinhaça é um subproduto derivado do processo de produção de álcool na taxa média de $13 \mathrm{~L}$ por litro de álcool produzido. Este resíduo, por sua vez, ao ser empregado na fertirrigação da própria canade-açúcar, recicla os nutrientes extraídos do caldo destilado e é considerado uma das grandes revoluções no manejo da cultura da cana-de-açúcar no Brasil (Orlando Filho et al., 1981).

Neste contexto e fundamentado na agricultura sustentável devido à reciclagem de água e nutrientes para o solo cultivado, o manejo da cana-de-açúcar que contempla a aplicação de vinhaça, também mitiga os efeitos dessa monocultura sobre o ambiente. Neste sentido, o controle da aplicação da vinhaça no solo pelas usinas alcooleiras e seus prováveis efeitos sobre o ambiente, devem ser controlados com monitoramento contínuo.

As mudanças nas propriedades químicas do solo promovidas pela aplicação da vinhaça podem alterar a estabilidade de agregados e a dispersão de argila do solo, influenciando na sua compactação, cujas principais consequências desta compactação são: o aumento da densidade, a diminuição do tamanho dos poros e a redução da condutividade hidráulica (Klein \& Libardi, 2002).

Com a utilização do solo para as atividades agrícolas, é comum serem encontradas camadas mais compactadas na parte superior do seu perfil. Nessas áreas intensivamente utilizadas para a produção agrícola, os valores de densidade do solo são mais elevados, afetando negativamente a aeração e prejudicando a penetração e proliferação de raízes no solo (Corsini, 1992; Corsini \& Ferraudo, 1999).

Apesar do aumento temporário do $\mathrm{pH}$ em virtude da aplicação da vinhaça no solo, Silva \& Cabeda (2005) e Silva et al. (2006a), estudando três sistemas de manejo do solo cultivado com cana-de-açúcar, sendo um de sequeiro, um irrigado e um com aplicação de vinhaça, constataram efeitos benéficos da vinhaça sobre as propriedades físicas e químicas dos solos, devido ao aumento da capacidade de retenção de umidade, porosidade, concentração de potássio e condutividade elétrica.

Silva et al. (2006b), verificaram que o efeito dos sistemas de manejo nos valores de matéria seca de raízes da cana-de-açúcar foi significativo com o solo que recebeu vinhaça, apresentando os maiores valores nas camadas de $0-0,2$ e $0,2-0,4 \mathrm{~m}$, em relação aos solos sob os sistemas sequeiro e irrigado. Os autores reforçam ainda, que o maior desenvolvimento do sistema radicular da cana-de-açúcar no solo com vinhaça o que reflete sem dúvida, a melhor condição química deste solo, promovida pela aplicação desse subproduto, em relação aos solos sob os sistemas sequeiro e irrigado.

Korndörfer et al. (1989), observaram que, ao longo do perfil do solo, não há diferença na distribuição de raízes entre as variedades de cana-de-açúcar; ficando entre 89 a $92 \%$ na camada de $0,30 \mathrm{~m}$ na cana planta e entre 85 a $92 \%$ até $0,40 \mathrm{~m}$ na cana soca. Vasconcelos (2002), observou que a morte ou renovação do sistema radicular não é causada pela colheita da cultura e, sim, pela deficiência hídrica, independente da fase de desenvolvimento.
Com o exposto objetivou-se, com a realização do presente trabalho, estudar a influência da aplicação de vinhaça durante vários anos na produtividade, resistência a penetração e distribuição do sistema radicular da cultura de cana-de-açúcar no noroeste do estado do Paraná.

\section{Material e mÉTOdos}

O presente trabalho foi realizado em Cidade Gaúcha, região noroeste do estado do Paraná. O clima da região é subtropical úmido mesotérmico, conforme classificação de Köppen, verões quentes com tendência de concentração das chuvas, temperatura anual média de $22^{\circ} \mathrm{C}$, invernos com geadas pouco frequentes sem estação seca definida. O solo da região é classificado como Latossolo Vermelho de textura areia franca (EMBRAPA, 1999).

Os tratamentos constaram de áreas de cultivo de cana-deaçúcar que receberam aplicação de vinhaça durante 1, 2, 3, 4, 12 e 20 anos, respectivamente, e uma área testemunha sem aplicação. Para as áreas que receberam vinhaça, cada ano corresponde a uma aplicação de $150 \mathrm{~m}^{3} \mathrm{ha}^{-1}$, efetuada por um canhão autopropelido com taxa de aplicação média de $12,5 \mathrm{~mm} \mathrm{~h}^{-1}$.

Determinou-se a compactação do solo entre as linhas de plantio, com três repetições, empregando-se um penetrômetro de cone, com peso do martelete de $4 \mathrm{~kg}$, com curso de queda livre de $400 \mathrm{~mm}$, cone ângulo sólido de $30^{\circ}$, área da base 1,28 $\mathrm{cm}^{2}$ e o diâmetro da haste que penetra no solo de $9,5 \mathrm{~mm}$. A avaliação dos resultados foi realizada conforme Sene et al. (1985), adaptado por Canarache (1990), que sugere limites de classes de resistência dos solos a penetração e graus de limitação ao crescimento das raízes. Os autores classificam como sem limitação, valores abaixo de 1,1 MPa, pouca limitação, valores entre 1,1 e 2,5 MPa, algumas limitações valores entre 2,6 a 5,0 MPa e sérias limitações, valores acima de 5,1 MPa. O teor de água do solo determinado na data da avaliação da resistência a penetração está apresentado na Tabela 1.

Tabela 1. Teor de água do solo em \% de massa na data das avaliações da resistência a penetração

\begin{tabular}{cccccccc}
\hline $\begin{array}{c}\text { Profundidade } \\
(\mathbf{m})\end{array}$ & \multicolumn{7}{c}{ Tratamentos (anos de aplicações) } \\
\cline { 2 - 8 } $0-0,15$ & Testemunha & $\mathbf{1}$ & $\mathbf{2}$ & $\mathbf{3}$ & $\mathbf{4}$ & $\mathbf{1 2}$ & $\mathbf{2 0}$ \\
$0,15-0,30$ & 8,9 & 5,8 & 8,4 & 6,0 & 12,9 & 9,8 & 5,0 \\
$0,30-0,50$ & 6,3 & 7,8 & 4,5 & 7,6 & 13,4 & 9,4 & 9,0 \\
\hline
\end{tabular}

As análises químicas do solo foram realizadas pelo chamado método Embrapa, o qual compreende as extrações de $\mathrm{P}$ e K, com a solução $\mathrm{Mehlich}^{-1}$, de $\mathrm{Al}, \mathrm{Ca}$ e $\mathrm{Mg}$ com o $\mathrm{KCl}$; as determinações do $\mathrm{pH}$ em água e do carbono ou da matéria orgânica por método colorimétrico, calibrado com o método Walkey-Black. Tomou-se a distribuição vertical do sistema radicular margeando-se a linha de plantio com o uso de um amostrador cilíndrico $(0,102 \mathrm{~m}$ de diâmetro, $0,10 \mathrm{~m}$ de altura), adaptado do método de tradagem citado por Vasconcelos (2002), introduzido no perfil do solo em intervalos de $0,10 \mathrm{~m}$ até a profundidade de $0,50 \mathrm{~m}$. As amostras de raízes coletadas foram peneiradas com malha de $2 \mathrm{~mm}$ e secadas em estufa com 
circulação forçada de ar, a $70^{\circ} \mathrm{C}$, por $96 \mathrm{~h}$, para posterior pesagem.

Os valores de produtividade de cana-de-açúcar das áreas avaliadas foram fornecidos pela usina na qual se realizou o trabalho. Os valores obtidos foram quantificados pela massa total que foi retirada da área durante a época de corte.

\section{RESULTADOS E DISCUSSÃO}

Observa-se, na Figura 1, que a área testemunha apresentou os menores valores de resistência a penetração e, de acordo com Canarache (1990), apresentou "algumas limitações" ao crescimento das raízes, a partir de 0,30 m de profundidade; já as áreas com 1, 2, 3 e 4 anos de aplicação de vinhaça começaram a apresentar "algumas limitações" ao crescimento das raízes, a partir dos 0,14 m de profundidade, não ultrapassando este valor até a profundidade de $0,50 \mathrm{~m}$, exceto a área que recebeu aplicação de vinhaça durante 2 anos, que apresentou valores de resistência a penetração mais acentuados a partir de $0,23 \mathrm{~m}$, implicando em "sérias limitações" para o crescimento das raízes. As áreas com 12 e 20 anos foram as que apresentaram condições mais restritivas, oferecendo "algumas limitações" após 0,10 e $0,08 \mathrm{~m}$, respectivamente, e a partir da profundidade de $0,22 \mathrm{~m}$ até aproximadamente $0,36 \mathrm{~m}$, apresentaram "sérias limitações" para o crescimento das raízes.

Até $0,05 \mathrm{~m}$ de profundidade não se observaram diferenças entre os tratamentos para resistência do solo a penetração do cone mas, a partir desta profundidade até $0,10 \mathrm{~m}$, os solos que receberam vinhaça durante 12 e 20 anos, obtiveram valores de

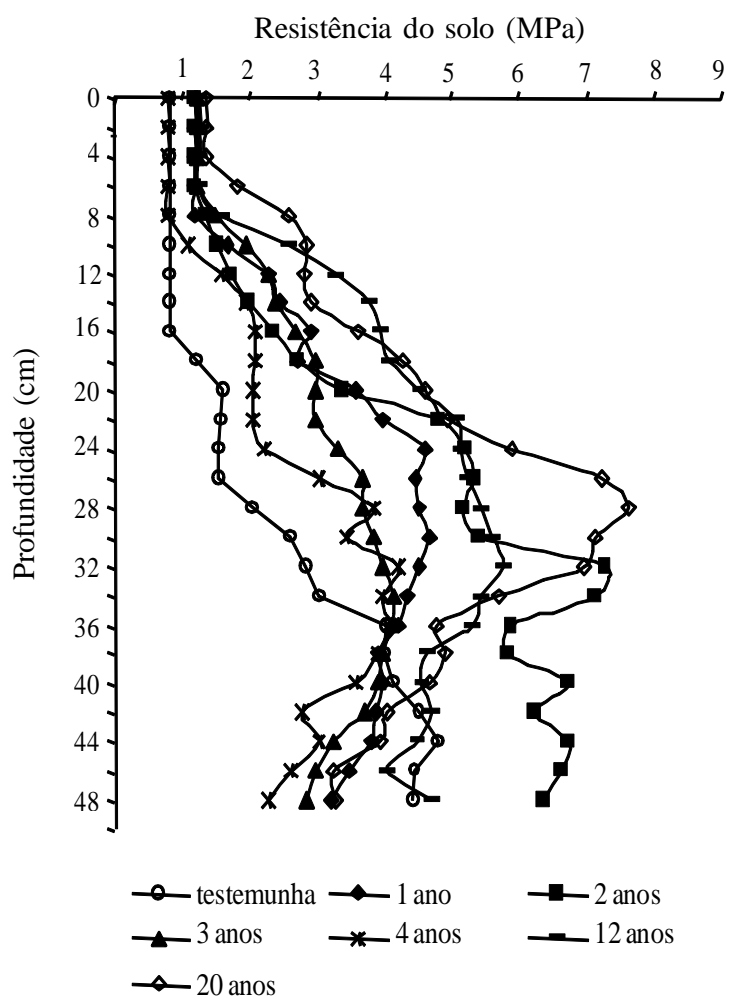

Figura 1. Resistência do solo a penetração do cone em M Pa até $0,50 \mathrm{~m}$ de profundidade para diferentes anos de aplicação de vinhaça
2,8 Mpa, mais elevados; a 0,15 m de profundidade, a resistência a penetração dos solos tratados com vinhaça se afastou dos valores encontrados para a testemunha, ficando entre 2,0 e 4,0 $\mathrm{Mpa}$, enquanto a testemunha permanece com 0,8 MPa.

Aos $0,20 \mathrm{~m}$ de profundidade a resistência a penetração do solo testemunha aumenta para 1,5 $\mathrm{MPa}$ e os valores da resistência a penetração dos solos tratados com vinhaça durante 12 e 20 anos, apresentam as maiores resistências a penetração, 5,0 MPa. A partir desta profundidade os valores de resistência a penetração tendem a diminuir ficando entre 2,2 e 4,6 MPa em 0,50 m de profundidade. O tratamento que se manteve mais próximo da testemunha foi o que recebeu vinhaça por 4 anos e os maiores valores de resistência a penetração, 7,8 Mpa, ocorreram a aproximadamente $0,28 \mathrm{~m}$ de profundidade na área que recebeu vinhaça por 20 anos.

Na camada mais superficial do solo, os valores médios de resistência a penetração tenderam a apresentar uma variação muito grande; isto se deve ao fato desta camada ser a mais influenciada pelo tráfego de máquinas em função de sua mobilização. Em relação às camadas mais profundas, os solos mais arenosos estão sujeitos a maior compactação nas maiores profundidades, em virtude da deposição das partículas de menor diâmetro, como observam Iaia et al. (2006), o que explica os maiores valores de resistência a penetração ao longo do perfil estudado. Estes autores estudaram o uso de um penetrômetro eletrônico na avaliação da resistência de dois Latossolos cultivados com cana-de-açúcar.

$\mathrm{Na}$ Tabela 2 estão os valores de densidade do solo em três camadas, para todas as áreas estudadas; observa-se que todas as áreas que apresentaram a maior densidade na camada de 0,15-0,30 m, indicaram, também, maior resistência a penetração nesta camada; a área que recebeu aplicação de vinhaça durante 12 anos foi a única com a maior densidade na camada superficial de 0-0,15 m, como pode ser observado na Figura 1. Merotto Jr \& Mundstock (1999), verificaram aumento exponencial da resistência do solo à penetração, com incremento da densidade do solo, o que dá um indicatico de que a densidade é a medida quantitativa mais direta da compactação, citado por Lanzanova et al. (2007). Este indicativo pôde ser observado nos dados avaliados.

Tabela 2. Densidade do solo $\mathrm{em} \mathrm{kg} \mathrm{m}^{-3}$ até $0,50 \mathrm{~m}$ de profundidade

\begin{tabular}{cccccccc}
\hline $\begin{array}{c}\text { Profundidade } \\
\text { (m) }\end{array}$ & \multicolumn{7}{c}{ Tratamentos (anos de aplicação) } \\
\cline { 2 - 8 } $0-0,15$ & Testemunha & $\mathbf{1}$ & $\mathbf{2}$ & $\mathbf{3}$ & $\mathbf{4}$ & $\mathbf{1 2}$ & $\mathbf{2 0}$ \\
$0,15-0,30$ & 1600 & 1628 & 1341 & 1664 & 1808 & 1879 & 1702 \\
$0,30-0,50$ & 1794 & 1844 & 1840 & 1750 & 1862 & 1846 & 1820 \\
\hline
\end{tabular}

Os valores médios de massa seca das raízes encontrados para as áreas Testemunha, 3, 4, 12 e 20 anos de aplicação de vinhaça, foram, respectivamente, 0,566, 0,763, 0,659, 0,554 e $0,668 \mathrm{~kg} \mathrm{~m}^{-3}$. Observa-se que a maior concentração de raízes até $0,50 \mathrm{~m}$ de profundidade ocorreu no tratamento com 3 anos de aplicação; não se observou, porém, diferença entre os valores encontrados pelo teste de Scott Knot para $\mathrm{p} \leq 0,05$.

Observando-se, na Figura 2, a distribuição de raízes, é possível notar que a maior concentração das raízes se encontra 
na camada de 0 a 0,20 m, corroborando com Medina et al. (2002) que, estudando o sistema radicular da cana-de-açúcar em Latossolo Vermelho, encontraram resultado semelhante para a camada de 0 a $0,25 \mathrm{~m}$.

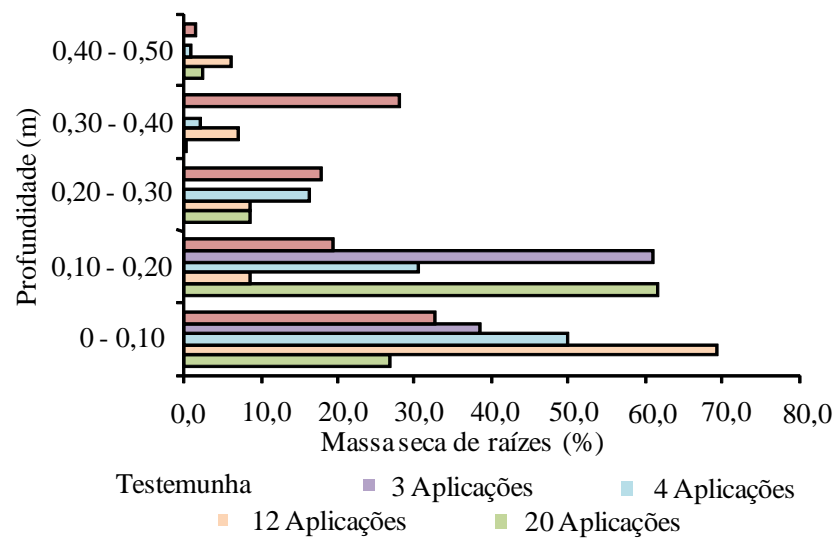

Figura 2. D istribuição das raízes de cana-de-açúcar a 0,10; 0,$20 ; 0,30 ; 0,40$ e $0,50 \mathrm{~m}$ de profundidade

Na área com 12 anos de aplicação $99 \%$ das raízes se concentraram na camada de 0 a $0,20 \mathrm{~m}$ e apenas $1 \%$ superou esta camada, o que pode ser devido à elevação abrupta da resistência a penetração que ocorreu nesta área, entre 0,8 e $0,14 \mathrm{~m}$ de profundidade, quando a resistência a penetração passou de 1,2 para 3,8 MPa, enquanto nos outros tratamentos o aumento da resistência a penetração nesta profundidade ficou entre 1,2 e 2,8 Mpa.

Para as demais áreas observa-se que a distribuição de raízes foi decrescente ao longo do perfil do solo e que nas áreas com 3 e 4 anos de aplicação de vinhaça a distribuição das raízes até os $0,40 \mathrm{~m}$ foi semelhante.

Entre 0,20 e $0,40 \mathrm{~m}$ de profundidade no perfil do solo é possível observar que a distribuição das raízes aumentou com o tempo de aplicação de vinhaça, com exceção da área que recebeu aplicação durante 12 anos; este aumento pode ser atribuído ao efeito da aplicação da vinhaça, uma vez que o manejo do solo não exerce influência nesta camada.

Imhoff et al. (2000) e Merotto Jr. \& Mundstock (1999), observam que valores de resistência a penetração acima de 2 MPa são considerados limitantes para o desenvolvimento radicular de várias culturas anuais, como trigo, milho e algodão; contudo, verifica-se que para as condições do estudo os valores de resistência a penetração nas camadas de 0,20 e 0,40 $\mathrm{m}$ de profundidade, considerados restritivos ao desenvolvimento das raízes, não foram suficientes para impedir o desenvolvimento do sistema radicular da cana-de-açúcar.

Silva et al. (2006a), estudando as alterações físicas e químicas de um Argissolo amarelo sob diferentes sistemas de uso e manejo, verificaram que o solo que recebeu vinhaça apresentou os maiores valores de massa seca de raízes nas camadas de 0 0,20 e 0,20-0,40 m. Os autores atribuíram este maior desenvolvimento do sistema radicular ao fato da aplicação de vinhaça ter proporcionado melhor condição química nessas camadas.

Observa-se, na Figura 3, que para as áreas que receberam aplicações de vinhaça durante 1, 12 e 20 anos, os valores de fertilidade atual foram mais elevados na camada de 0,20-0,40 m, estando esses relativamente próximos aos da camada de 0 0,20m. Para as áreas com aplicação de vinhaça durante 2, 3 e 4 anos, os valores de fertilidade atual foram mais acentuados na camada superficial do solo (0-0,20 m). Devido a esta maior quantidade de íons trocáveis na camada superficial do solo, houve também maior desenvolvimento do sistema radicular em todas as áreas estudadas.

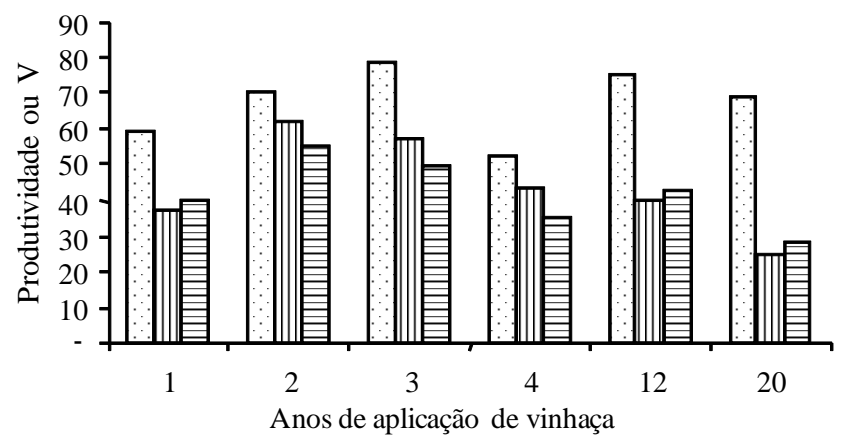

口 Produtividade $\mathrm{Mg} \mathrm{ha}^{-1}$ 匹 V\% 0 - 0,20 घ V\% 0,20 - 0,40

Figura 3. Produtividade média da cultura da cana-de-açúcar e saturação por base (V\%) atual em duas profundidades em função dos anos de aplicação de vinhaça

Gava et al. (2001) relataram que o aumento da quantidade de raízes no perfil do solo é muito importante para garantir o desenvolvimento da cultura, uma vez que raízes mais profundas dão melhor sustentabilidade e contribuem para a absorção de água e nutrientes, porém uma quantidade menor de raízes no perfil do solo, encontrada neste trabalho, não implicou em uma produtividade menor.

Na Figura 4 estão as concentrações de K, Ca e Mg para todas as áreas estudadas; observa-se, com exceção das áreas com 2 e 3 anos de aplicação de vinhaça, que para todas as áreas estudadas a concentração de $\mathrm{K}$ foi mais elevada na camada superficial do solo e isto ocorreu, possivelmente, pela maior retenção do K nessa camada em virtude do maior contato entre os colóides do solo e a vinhaça. Observa-se ainda que as áreas que receberam aplicações de vinhaça apresentaram maior teor de $\mathrm{K}$ em relação à área sem aplicação de vinhaça. Resultados semelhantes obtiveram Bebé et al. (2009), ao avaliarem solos sob diferentes períodos de aplicação com vinhaça, e por Brito

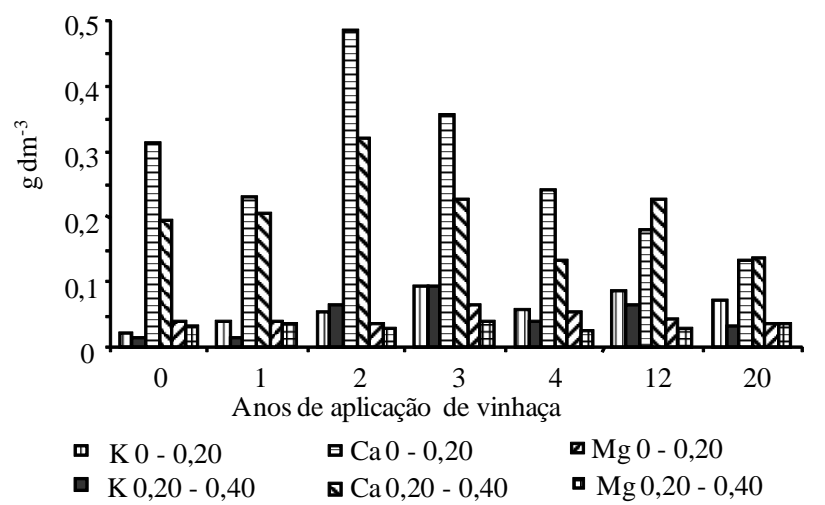

Figura 4. Concentração de $\mathrm{K}, \mathrm{Ca}$ e $\mathrm{Mg}\left(\mathrm{g} \mathrm{dm}^{-3}\right)$ em duas profundidades em função dos anos de aplicação de vinhaça 
et al. (2005) ao estudarem os teores de potássio e sódio no lixiviado e em solos após a aplicação de vinhaça.

Para a área com 2 anos de aplicação de vinhaça, verifica-se que a concentração de $\mathrm{K}$ foi mais elevada na camada de $0-0,20$ a 0,20-0,40 m e para a área com 3 anos de aplicação a concentração de $\mathrm{K}$ foi praticamente a mesma, em ambas as camadas estudadas. Observa-se ainda que nas áreas com maior disponibilidade de K na camada de 0,20-0,40 m (áreas com 2, 3 e 12 anos de aplicação de vinhaça) ocorreram as maiores produtividades de cana-de-açúcar.

$\mathrm{O}$ Ca foi encontrado em maiores concentrações em relação aos demais nutrientes e decresceu após 2 anos de aplicação de vinhaça, acompanhando a fertilidade atual dos solos, porém não tendo ligação direta com a produtividade, assim como o $\mathrm{Mg}$; já o K, apesar de não se apresentar em maior concentração, teve relação direta com a produtividade.

$\mathrm{O}$ pH, como pode ser observado na Figura 5, apresentou pequenas variações em relação à profundidade e diminuição com o tempo de aplicação de vinhaça, tornando o solo ácido, com o passar dos anos; mesmo assim, a diminuição do $\mathrm{pH}$ ao longo do tempo de aplicação de vinhaça não afetou a produtividade nas áreas estudadas.

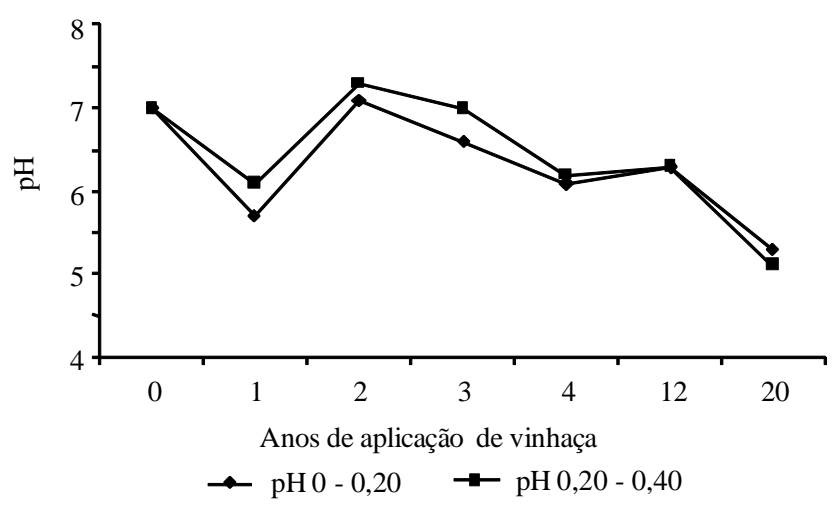

Figura 5. pH do solo de 0 a 0,20 e de 0,20 a 0,40 m de profundidade em função dos anos de aplicação de vinhaça

De acordo com Maia \& Ribeiro (2004) as camadas mais profundas do solo geralmente apresentam maior acidez em relação às camadas superficiais devido à aplicação de corretivos e adubações que favorecem o aumento do $\mathrm{pH}$ do solo.

Bebé et al. (2009), verificaram que a aplicação de vinhaça ao longo dos anos não alterou o pH dos solos estudados. Diferentemente, Brito et al. (2005) verificaram aumento do pH em todos os solos estudados e com as doses de vinhaça de 350 e $700 \mathrm{~m}^{3} \mathrm{ha}^{-1}$.

\section{CONCLUSÕES}

1. A distribuição de raízes decresce até $0,20 \mathrm{~m}$ de profundidade e na profundidade de 0,20 a $0,40 \mathrm{~m}$ mostra-se crescente com o aumento do tempo de aplicação de vinhaça, com exceção da área com 12 anos de aplicação.

2. Valores de resistência a penetração considerados restritivos para o desenvolvimento de raízes, não foram suficientes para impedir o seu desenvolvimento, até a profundidade de 0,50 m, na área que recebeu aplicação de vinhaça por 20 anos.

3. O aumento da quantidade de raízes no perfil do solo não implicou em maiores produtividades para cultura de cana-deaçúcar.

4. A produtividade da cana-de-açúcar mostrou-se sensível ao acréscimo da concentração de K no solo.

5. Houve uma tendência de decréscimo do $\mathrm{pH}$ do solo conforme aumentou-se os anos de aplicação de vinhaça.

\section{LITERATURA CITADA}

Bebé, F. V.; Rolim, M. M.; Pedrosa, E. M. R.; Silva, G. B.; Oliveira, V. S. Avaliação de solos sob diferentes períodos de aplicação com vinhaça. Revista Brasileira de Engenharia Agrícola e Ambiental, v.13, p.781-787, 2009.

Brito, F. L.; Rolim, M. M.; Pedrosa, E. M. R. Teores de potássio e sódio no lixiviado e em solos após a aplicação de vinhaça. Revista Brasileira de Engenharia Agrícola e Ambiental, v.9, p.52-56, 2005.

Canarache, A. PENETR - A generalized semi-empirical model estimating soil resistance to penetration. Soil and Tillage Research, v.16, p.51-70, 1990.

Corsini, P. C. Problemas causados pela compactação dos solos. STAB, v.18, p.8-12, 1992.

Corsini, P. C.; Ferraudo, A. S. Efeitos de sistemas de cultivo na densidade e na macroporosidade do solo e no desenvolvimento radicular do milho em Latossolo Roxo. Pesquisa Agropecuária Brasileira, v.34, p.289-298, 1999.

EMBRAPA - Empresa Brasileira de Pesquisa Agropecuária. Centro Nacional de Pesquisa de Solos (Rio de Janeiro, RJ). Sistema brasileiro de classificação de solos. Brasília: Embrapa SPI; Embrapa CNPS, 1999. 412p.

Gava, G. J. C.; Trivelin, P. C. O.; Oliveira, M. W.; Penatti, C. P. Crescimento e acúmulo de nitrogênio em cana-de-açúcar cultivada em solo coberto com palhada. Pesquisa Agropecuária Brasileira, v.36, p.1347-1354, 2001.

Iaia, A. M.; Maia, J. C. S.; Kim, M. E. Uso do penetrômetro eletrônico na avaliação da resistência do solo cultivado com cana-de-açúcar. Revista Brasileira de Engenharia Agrícola e Ambiental, v.10, p.523-530, 2006.

Imhoff, S.; Silva, A. P.; Tormena, C. A. Aplicação da curva de resistência no controle da qualidade física de um solo sob pastagem. Pesquisa Agropecuária Brasileira, v.35, p.14931500, 2000.

Klein, V. A.; Libardi, P. L. Densidade e distribuição de diâmetro dos poros de um Latossolo Vermelho, sob diferentes sistemas de uso e manejo. Revista Brasileira de Ciência do Solo, v.26, p.857-867, 2002.

Korndörfer, G. H.; Primavesi, O.; Deuber, R. Crescimento e distribuição do sistema radicular da cana-de-açúcar em solo LVA. Boletim Técnico Coopersucar, v.47, p.32-36, 1989.

Lanzanova, E. L.; Nicoloso, S. R. da; Loyato, T.; Eltz, F. L. F.; Amado, T. J. C.; Reinert, J. D. Atributos físicos do solo em sistema de integração lavoura-pecuária sob plantio direto. Revista Brasileira de Ciência do Solo, v.31, p.1131-1140, 2007. 
Maia, J. L. T.; Ribeiro, M. R. Cultivo contínuo da cana-deaçúcar e modificações químicas de um Argissolo Amarelo fragipânico. Pesquisa Agropecuária Brasileira, v.39, p.11271132, 2004

Medina, C. C.; Neves, C. S. V. J.; Fonseca, C. B.; Torreti, A. F. Crescimento radicular e produtividade de cana-de-açúcar em função de doses de vinhaça em fertirrigação. Semina: Ciências Agrárias, v.23, p.179-184, 2002.

Merotto Jr., A.; Mundstock, C. M. Wheat root growth as affected by soil strength. Revista Brasileira de Ciência do Solo, v.23, p. 197-202, 1999.

Orlando Filho, J.; Zambello Júnior, E.; Rodella, A. A. Calibração de potássio no solo e recomendação de adubação para a cana-de-açúcar. Brasil Açucareiro, v.97, p.18-24, 1981.

Sene, M.; Vepraskas, M. J.; Naderman, G. C.; Denton, H. P. Relationships of soil texture and structure to corn yield response to subsoiling. Soil Science Society of America Journal, v.49, p.422-427, 1985.
Silva, A. J. N.; Cabeda, M. S. V. Influência de diferentes sistemas de uso e manejo na coesão, resistência ao cisalhamento e óxidos de Fe, $\mathrm{Si}$ e $\mathrm{Al}$ em solo de tabuleiro costeiro de Alagoas. Revista Brasileira de Ciência do Solo, v.29, p.447$457,2005$.

Silva, A. J. N. da; Cabeda, M. S. V.; Carvalho, F. G. de. Matéria orgânica e propriedades físicas de um Argissolo Amarelo Coeso sob sistemas de manejo com cana-de-açúcar. Revista Brasileira de Engenharia Agrícola e Ambiental, v.10, p.759585,2006 .

Silva, A. J. N. da; Cabeda, M. S. V.; Carvalho, F. G. de; Lima, J. F. W. F. Alterações físicas e químicas de um Argissolo Amarelo sob diferentes sistemas de uso e manejo. Revista Brasileira de Engenharia Agrícola e Ambiental, v.10, p.76-83, 2006 b.

Vasconcelos, A. C. M. Desenvolvimento do sistema radicular e da parte aérea de socas de cana-de-açúcar sob dois sistemas de colheita. Jaboticabal: Universidade Estadual Paulista, 2002. 140p. Tese Doutorado 